\title{
Indoor and outdoor malaria vector surveillance in western Kenya: implications for better understanding of residual transmission
}

Teshome Degefa ${ }^{1,2}{ }^{0}$, Delenasaw Yewhalaw ${ }^{1,3}$, Guofa Zhou ${ }^{4}$, Ming-chieh Lee ${ }^{4}$, Harrysone Atieli2, ${ }^{2,5}$ Andrew K. Githeko ${ }^{2}$ and Guiyun Yan ${ }^{4^{*}}$

\begin{abstract}
Background: The widespread use of indoor-based malaria vector control interventions has been shown to alter the behaviour of vectors in Africa. There is an increasing concern that such changes could sustain residual transmission. This study was conducted to assess vector species composition, feeding behaviour and their contribution to indoor and outdoor malaria transmission in western Kenya.

Methods: Anopheles mosquito collections were carried out from September 2015 to April 2016 in Ahero and Iguhu sites, western Kenya using CDC light traps (indoor and outdoor), pyrethrum spray catches (PSCs) (indoor) and pit shelters (outdoor). Species within Anopheles gambiae s.l. and Anopheles funestus s.l. were identified using polymerase chain reaction (PCR). Enzyme-linked immunosorbent assay (ELISA) was used to determine mosquito blood meal sources and sporozoite infections.

Results: A total of 10,864 female Anopheles mosquitoes comprising An. gambiae s.l. (71.4\%), An. funestus s.l. (12.3\%), Anopheles coustani (9.2\%) and Anopheles pharoensis (7.1\%) were collected. The majority (61.8\%) of the anopheline mosquitoes were collected outdoors. PCR result $(n=581)$ revealed that $98.9 \%$ An. arabiensis and $1.1 \%$ An. gambiae s.s. constituted An. gambiae s.l. in Ahero while this was $87 \%$ An. gambiae s.s. and $13 \%$ An. arabiensis in Iguhu. Of the 108 An. funestus s.l. analysed by PCR, 98.1\% belonged to An. funestus s.s. and 1.9\% to Anopheles leesoni. The human blood index (HBI) and bovine blood index (BBI) of An. arabiensis was 2.5 and $73.1 \%$, respectively. Anopheles gambiae s.s. had $\mathrm{HBI}$ and $\mathrm{BBI}$ of 50 and 28\%, respectively. The $\mathrm{HBI}$ and $\mathrm{BBI}$ of An. funestus was 60 and 22.3\%, respectively. Forage ratio estimate revealed that An. arabiensis preferred to feed on cattle, An. gambiae s.s. showed preference for both human and cattle, while An. funestus preferred human over other hosts. In Ahero, the sporozoite rates for An. arabiensis and An. funestus were 0.16 and $1.8 \%$, respectively, whereas in Iguhu, the sporozoite rates for An. gambiae s.s. and An. funestus were 2.3 and 2.4\%, respectively. In Ahero, the estimated indoor and outdoor entomological inoculation rate (EIR) was 108.6 infective bites/person/year (79.0 from An. funestus and 29.6 from An. arabiensis) and 43.5 infective bites/person/year (27.9 from An. arabiensis and 15.6 from An. funestus), respectively. In Iguhu, the estimated indoor and outdoor EIR was 24.5 infective bites/person/year (18.8 from An. gambiae s.s. and 5.7 from An. funestus) and 5.5 infective bites/person/year (all from An. gambiae s.s.), respectively.
\end{abstract}

Conclusion: Anopheles gambiae s.s. showed an increasing tendency to feed on cattle. Anopheles arabiensis was highly zoophagic, whereas An. funestus showed anthropophagic behaviour. While the majority of malaria transmission

\footnotetext{
*Correspondence: guiyuny@uci.edu

${ }^{4}$ Program in Public Health, College of Health Sciences, University

of California at Irvine, Irvine, CA 92697, USA

Full list of author information is available at the end of the article
} 
occurred indoor, the magnitude of outdoor transmission was considerably high. Additional control tools that complement the existing interventions are required to control residual transmission.

Keywords: Malaria vectors, Surveillance, Behavior, Residual transmission, Kenya

\section{Background}

Malaria is a serious vector-borne disease affecting hundreds of millions of people in Africa. In the past decade, a substantial reduction in malaria incidence has been observed in Africa, including Kenya, due to the scaleup of interventions. Vector control is one of the key elements in achieving the remarkable decline of malaria, with the scale-up of insecticide-treated nets (ITNs) and expansion of indoor residual spray (IRS) contributing significantly [1-4]. The proportion of households owning at least one ITN in sub-Saharan Africa is estimated to have risen from 3\% in 2000 to $67 \%$ in 2015 [1]. In western Kenya, the ITN ownership rose from $12.8 \%$ in 2004 to over $80 \%$ in 2015 [5-7].

Despite the progress made in scaling-up of the interventions, malaria transmission continues to occur. Several factors are responsible for this transmission, including the spread of insecticide resistance [5, 8], shift in vector species composition [9-12] and increasing vector behavioural change towards more zoophagic, exophagic and/or exophilic tendencies following the widespread use of ITNs and IRS [13, 14].

Recent reports from East Africa showed strong evidence for shifts in Anopheles gambiae sensu lato (s.l.) sibling species composition from predominantly endophagic An. gambiae sensu stricto (s.s.) to predominantly exophagic Anopheles arabiensis following the scale-up of ITNs $[9,11-13,15]$. In the lowlands of western Kenya, the proportion of An. gambiae s.s. declined from about 85\% in 1998 to $1 \%$ in 2009 following massive distribution of ITNs, whereas An. arabiensis population showed proportionate increment [9]. While malaria transmission by An. gambiae s.s. declined significantly, residual transmission continued to occur by An. arabiensis. Similarly, the proportion of An. arabiensis in the highlands of western Kenya has been increasing gradually [5].

Vector behavioural modifications including changes in host-preference, biting locations (indoor or outdoor) and resting behaviours have been reported following the long-term use of ITNs. For instance, ITN use was associated with shift in host preference of An. gambiae s.s. from human to cattle in Burkina Faso [16]. The long-term use of ITN increased the outdoor feeding proportion of An. gambiae s.s. in Bioko Island [17, 18] and Anopheles funestus in Tanzania [13]. However, these changes are not universal. A recent study in Asembo district of western Kenya showed that the majority of biting by $A n$. arabiensis, An. gambiae s.s. and An. funestus occurred indoors despite high ITN coverage in the area [19].

Malaria is mesoendemic and holoendemic in the highland and lowland areas of western Kenya, respectively [20]. The transmission is maintained by An. gambiae s.s., An. funestus and An. arabiensis. Anopheles gambiae s.s and An. funestus are considered as highly endophagic and anthropophagic, while An. arabiensis is considered as zoophagic and endophilic. However, most of the studies on their feeding and resting behaviour were conducted before the scale-up of vector control interventions [2123]. It is possible that the anthropophagic and endophilic individuals could shift to zoophagic and exophilic tendencies or be reduced to leave zoophagic and exophilic sibling species following the scale-up of ITNs as has been observed elsewhere.

In view of the increasing concern about residual malaria transmission in Africa, there is a pressing need to enhance our understanding about vector behaviours to evaluate the likely success of the current vector control tools. The main aim of this study was to assess vector species composition, feeding behaviour and their contribution to indoor and outdoor malaria transmission in western Kenya.

\section{Methods \\ Study sites}

The study was conducted in lowland and highland settings of western Kenya. Two sites were selected (Fig. 1): Ahero $\left(0^{\circ} .11^{\prime} \mathrm{S}, 34^{\circ} .55^{\prime} \mathrm{E}\right.$, altitude $\left.1162 \mathrm{~m}\right)$ in Kisumu county and Iguhu $\left(0^{\circ} .17^{\prime} \mathrm{N} ; 34^{\circ} .74^{\prime} \mathrm{E}\right.$, altitude 1430 $1580 \mathrm{~m}$ a.s.l) in Kakamega county. Iguhu site is highland characterized by valleys and depressions surrounded by densely populated hills whereas Ahero is lowland plain area. The sites have bimodal pattern of rainfall, with long rainy season from April to June, which triggers peak malaria transmission period and short rainy season from October to November with minimal transmission [24]. The hot and dry season is from January to March and this marks the lowest transmission [5]. Plasmodium falciparum is the predominant malaria species in the area and is transmitted by An. gambiae s.s., An. arabiensis and An. funestus $[5,25]$.

\section{Mosquito collections}

Adult mosquito collections were carried out monthly during the short rainy season (September to November) 


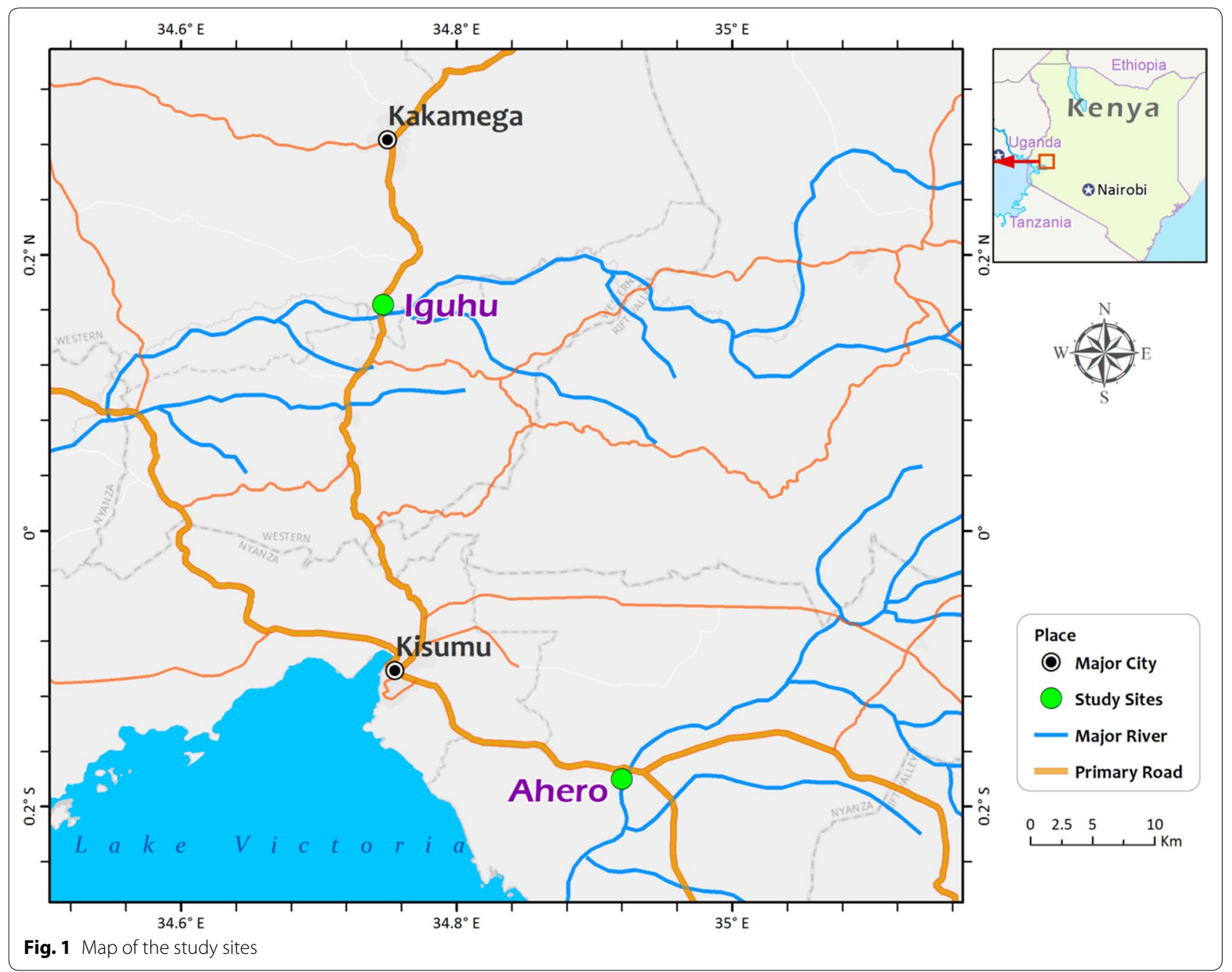

in 2015 and dry season (February to April) in 2016. Indoor and outdoor host-seeking mosquitoes were collected using Centers for Disease Control and Prevention (CDC) light traps (John W. Hock Ltd, Gainesville, FL., USA). For indoor host-seeking mosquito collection, CDC light traps were set inside houses near the bed at a height of $1.5 \mathrm{~m}$ from 18:00 to 06:00 $\mathrm{h}$ in twenty randomly selected houses per month in each study site. For the outdoor host-seeking mosquito sampling, CDC light traps were set outdoor in the vicinity (within $2 \mathrm{~m}$ ) of sentinel houses. The same houses were used for mosquito collections each month.

Indoor resting mosquitoes were sampled using pyrethrum spray catches (PSCs) from another twenty randomly selected houses from 06:00 to 09:00 h following standard protocol [26]. Outdoor resting mosquitoes were collected monthly in the mornings (06:00 to 09:00 h.) from twenty artificial outdoor pit shelters constructed according to the method of Muirhead-Thomson [27], in the compound of 20 selected houses in each study site. The collections were repeated using the same pit shelters each month.

Along with mosquito collection, data on the numbers of potential hosts in the study area including human, bovine, goat, dog and chicken were collected using questionnaire surveys. All collected mosquitoes were identified morphologically to species using keys [28]. Female Anopheles mosquitoes were further classified as unfed, blood fed, half-gravid and gravid. Each mosquito was kept in a labelled $1.5 \mathrm{ml}$ Eppendorf tube containing silica gel desiccant and cotton wool. Samples were stored at $-20{ }^{\circ} \mathrm{C}$ refrigerator at Climate and Human Health Research Laboratory of Kenya Medical Research Institute until used for further processing. 


\section{Identification of vector species complexes}

Members of An. gambiae s.l. and An. funestus s.l. groups were identified to species by polymerase chain reaction (PCR), following the protocols developed by Scott et al. for An. gambiae s.l. [29] and Koekemoer et al. for $A n$. funestus s.l. [30].

\section{Detection of blood meal sources}

The blood meal sources of freshly fed Anopheles mosquitoes were analyzed by a direct enzyme-linked immunosorbent assay (ELISA) [31] using human, bovine, goat, chicken and dog antibodies. Positive controls were included for each host during the assay. Laboratory reared unfed An. gambiae was used as negative control.

\section{Sporozoite ELISA}

Dried head and thorax of the preserved Anopheles mosquito specimens were carefully separated from the abdomen and tested for P. falciparum circumsporozoite proteins (CSPs) using sand-witch ELISA method [32, 33].

\section{Data analysis}

The density of adult anopheline mosquitoes was calculated as the number of female mosquitoes per trap/ night for each collection method. Analysis of variance (ANOVA) was used to compare malaria vector density between indoor and outdoor locations. $X^{2}$-test was employed to test the difference in vector species composition between indoor and outdoor.

Human blood index (HBI) was calculated as the proportion of Anopheles mosquitoes that fed on human over the total Anopheles tested for blood meal origins [34]. Bovine, goat, dog and chicken blood indices were also calculated in similar way. Mixed blood meals were included in the calculation of blood meal indices [35]. The forage ratio (FR), a measure of host preference by mosquitoes, was determined as the percent of engorged Anopheles mosquitoes which have fed on a given host (human, bovine, goat, dog or chicken) divided by the percent which it comprises in the total population of hosts available in the study area [36]. The FR $w_{i}$ for species $i$ was calculated as:

$$
w_{i}=\frac{o_{i}}{p_{i}}
$$

where $w_{i}$ is the FR for mosquito species $i, o_{i}$ is the proportion of host species $i$ in the blood meals, and $p_{i}$ is the proportion of host species $i$ available in the environment.

Statistical significance of the FR estimate for each host was based on overlap of the $95 \%$ confidence interval (CI) of the estimate with the value one [37]. A host was considered to have been preferred if the lower
95\% confidence limit for the FR estimate was greater than one. A host was inferred to have been avoided if the upper $95 \%$ confidence limit for the FR estimate was less than one. A host for which the $95 \%$ CI for its FR included one was considered to have been feed on opportunistically [37].

The sporozoite rate was estimated as the proportion of mosquitoes positive for $P$. falciparum CSPs over the total number tested. Annual entomological inoculation rate (EIR) was calculated from mosquito collections by CDC light traps using the formula, $1.605 \times$ (no. CSPpositive ELISA results from CDC light traps/no. mosquitoes tested $) \times($ no. mosquitoes collected from CDC light traps/no. trap-nights) $\times 365[38,39]$. The multiplication factor 1.605 is a conversion factor for CDC light trap catches vs. man biting catches [38]. The annual EIR of Anopheles mosquitoes collected by PSCs was determined as: (no. fed mosquitoes caught by PSC/no. human occupants who spent the night in the sprayed house) $\times$ (no. mosquitoes fed on human/no. mosquitoes tested for human blood meal $) \times($ PSC based sporozoite rate $) \times 365$ [40].

The annual EIR for Anopheles mosquitoes collected from pit shelters was also estimated as (no. fed mosquitoes caught in the pit shelters/no. human occupants who spent the night in a house nearest to the pit shelter) $\times$ (no. human fed mosquitoes/no. mosquitoes tested for human blood meal) $\times$ (sporozoite rate from pit shelters) $\times 365$. This formula was employed based on the assumption that all Anopheles mosquitoes collected from pit shelters have got their human blood meals from occupants of the nearest house, either indoor or outdoor.

Data were analyzed using STATISTICA 8.0 (StatSoft, Tulsa, USA) and SPSS version 20.0 (SPSS, Chicago, IL, USA) software packages. $\mathrm{p}<0.05$ was considered statistically significant during the analysis.

\section{Results}

Anopheline mosquito species composition and abundance A total of 10,864 female Anopheles mosquitoes belonging to four species were collected during the study period (Table 1). Anopheles gambiae s.l. was the predominant species accounting for $71.4 \%$ of the total captures, followed by An. funestus s.l. (12.3\%), Anopheles coustani complex (9.2\%) and Anopheles pharoensis (7.1\%). In addition, 3263 male anopheline mosquitoes and 5206 Culex species (males and females together) were collected over the study period. There was a significant difference in anopheline mosquito species co-occurrence between the study sites $\left(F_{1,952}=423.02, \mathrm{p}<0.0001\right)$. There was also significant difference in anopheline mosquito species co-occurrence between indoor and outdoor locations 
Table 1 Summary of female Anopheles mosquitoes collected from indoor and outdoor in lowland (Ahero) and highland (Iguhu) settings of western Kenya ( $n=120$ trap-nights for each trap)

\begin{tabular}{|c|c|c|c|c|c|}
\hline \multirow{2}{*}{$\begin{array}{l}\text { Study sites } \\
\text { and Anopheles } \\
\text { spp. }\end{array}$} & \multicolumn{2}{|l|}{ Indoor } & \multicolumn{2}{|l|}{ Outdoor } & \multirow[t]{2}{*}{ Total } \\
\hline & Light trap & PSC & Light trap & Pit shelter & \\
\hline \multicolumn{6}{|l|}{ Ahero } \\
\hline An. gambiae s.l. & 1592 & 1009 & 1636 & 3262 & 7499 \\
\hline An. funestus s.l. & 628 & 204 & 270 & 142 & 1244 \\
\hline An. coustani & 321 & 2 & 652 & 15 & 990 \\
\hline An.pharoensis & 78 & 0 & 688 & 0 & 766 \\
\hline \multicolumn{6}{|l|}{ Iguhu } \\
\hline An. gambiae s.l. & 108 & 51 & 56 & 41 & 256 \\
\hline An. funestus s.l. & 49 & 30 & 13 & 4 & 96 \\
\hline An. coustani & 3 & 0 & 10 & 0 & 13 \\
\hline Total & 2779 & 1296 & 3325 & 3464 & 10,864 \\
\hline
\end{tabular}

PSC, pyrethrum spray catch
$\left(F_{1,956}=29.44, \mathrm{p}<0.0001\right)$. The majority $(61.8 \%)$ of the anopheline mosquitoes were collected outdoors.

\section{Indoor and outdoor Anopheles mosquito density}

Figure 2 shows the mean indoor and outdoor density of host-seeking and resting female Anopheles mosquitoes. In Ahero, the mean outdoor resting density of $A n$. gambiae s.l. was significantly higher than indoor resting density $\left(t_{238}=8.45, \mathrm{p}<0.0001\right)$, whereas the difference in mean indoor and outdoor resting density of An. funestus s.l. was not significant ( $\mathrm{p}>0.05)$. The mean outdoor host-seeking density of $A n$. gambiae s.l. was also higher than indoor, although the difference was not statistically significant $\left(t_{238}=0.14, \mathrm{p}=0.889\right)$. The mean indoor host-seeking density of An. funestus s.l. was significantly higher than outdoor $\left(t_{238}=2.37, \mathrm{p}=0.019\right)$. Significantly higher outdoor host-seeking density than indoor was

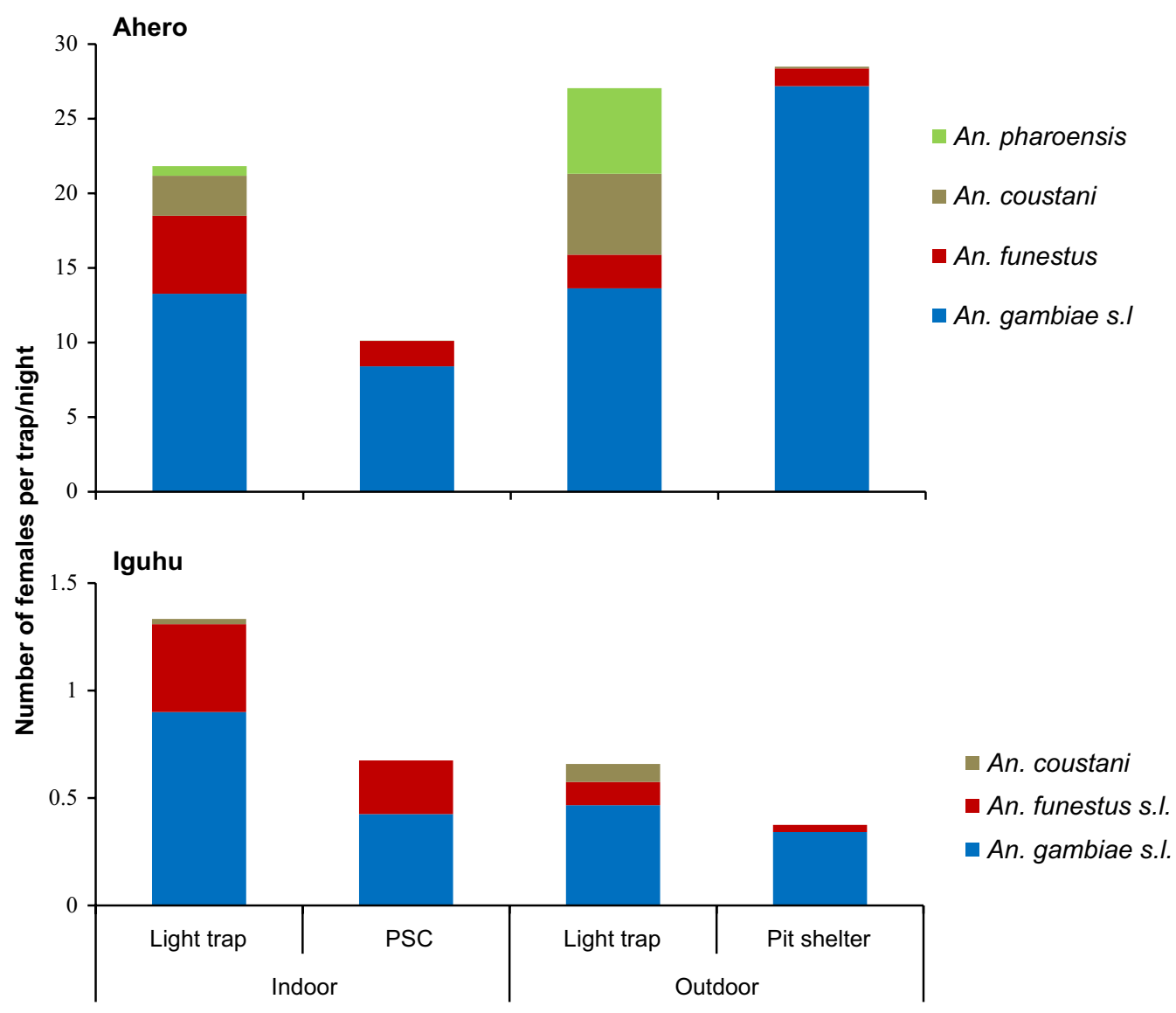

Locations and trapping methods

Fig. 2 Indoor and outdoor host-seeking and resting density of female Anopheles mosquitoes collected from Ahero and Iguhu, western Kenya 
observed for An. coustani $\left(t_{238}=2.589, \mathrm{p}=0.01\right)$ and $A n$. pharoensis $\left(t_{238}=4.923, \mathrm{p}<0.0001\right)$.

In Iguhu, the indoor host-seeking densities of An. gambiae s.l. and An. funestus s.l. were significantly higher than outdoor (An. gambiae s.l., $t_{238}=2.12, \mathrm{p}=0.034$; An. funestus s.l., $t_{238}=3.09, \mathrm{p}=0.002$ ). The difference in mean indoor and outdoor resting density of An. gambiae s.l. was not significant $\left(t_{238}=0.97, \mathrm{p}=0.335\right)$, while the mean indoor resting density of An. funestus s.l. was significantly higher $\left(t_{238}=3.23, \mathrm{p}=0.001\right)$ than outdoor.

\section{Composition of Anopheles gambiae and Anopheles funestus sibling species}

A total of 750 specimens (628 An. gambiae s.l. and 122 An. funestus s.l.) were analysed for identification of their respective sibling species. Of theses, 581 An. gambiae s.l. and 108 An. funestus s.l. specimens were successfully amplified and identified to species by PCR. Figure 3 shows member species of An. gambiae s.l. In Ahero, of the An. gambiae s.l. assayed, An. arabiensis and An. gambiae s.s accounted for 98.9 and $1.1 \%$, respectively. In contrast in Iguhu, An. gambiae s.s. and An. arabiensis constituted 87 and 13\%, respectively of the assayed $A n$. gambiae s.l. specimens. Overall, there was significant difference between indoor and outdoor locations in terms of An. gambiae s.l. species composition $\left(\mathrm{X}^{2}=26.443\right.$, $d f=1, \mathrm{p}<0.0001$ ). The proportion of An. arabiensis was higher outdoors than indoors. Of the 108 An. funestus s.l. confirmed by PCR, An. funestus s.s. (hereafter An. funestus) and Anopheles leesoni, accounted for 98.1 and 1.9\%, respectively. All the An. leesoni were from outdoor CDC light traps. The member species of An. funestus s.l. did not vary between the study sites.

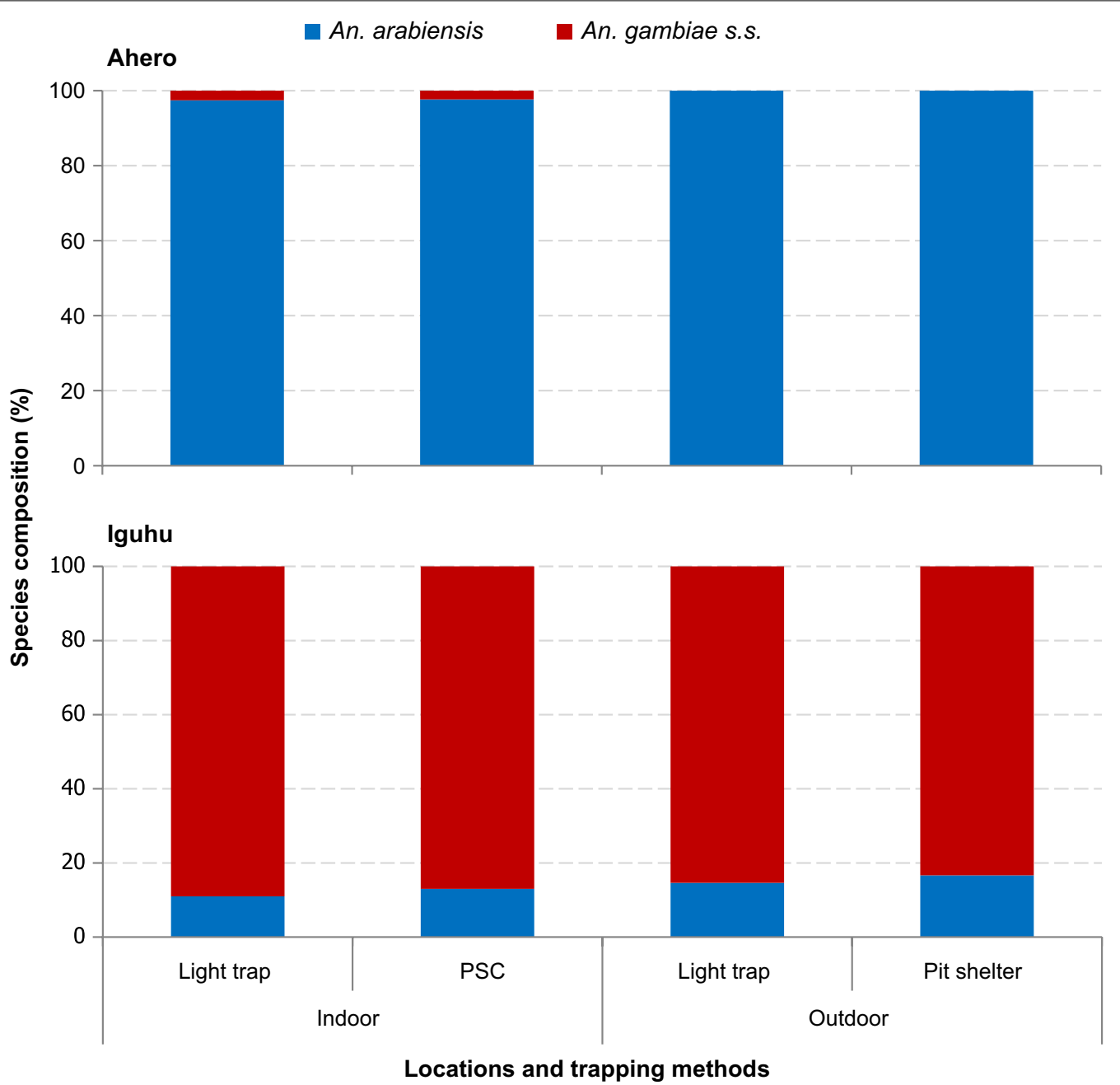

Fig. 3 Composition of Anopheles gambiae sibling species in Ahero and Iguhu, western Kenya 


\section{Physiological status}

In both indoor and outdoor collections, the majority (> 70\%) of the host-seeking anophelines were unfed. About $55 \%$ of the indoor resting and 39\% of the outdoor resting An. arabiensis were blood fed. One-third of the indoor resting and $31.7 \%$ of the outdoor resting An. gambiae s.s. were blood fed. About half of the indoor resting An. funestus were blood fed, while this was $11.6 \%$ for the outdoor resting An. funestus.

\section{Blood meal indices}

Table 2 shows the host blood indices of An. arabiensis and An. funestus in Ahero. The HBI of An. arabiensis from indoor CDC light traps and PSCs was 8.2 and 1.2\%, respectively, whereas the HBI of An. arabiensis from outdoor CDC traps and pit shelters was 3.4 and $0.7 \%$, respectively. The overall HBI of An. arabiensis was $2.5 \%$. The HBI of An. funestus from indoor CDC light traps and PSCs was 72.7 and $63.6 \%$, respectively, while the HBI of An. funestus from both outdoor CDC light traps and pit shelters was 50\%. In Ahero, the overall HBI for An. funestus was $62 \%$.

In contrast, the bovine blood index (BBI) of An. arabiensis from indoor CDC light traps, PSCs, outdoor CDC light traps and pit shelters was $62.3,66.7,50.8$, and $85.6 \%$, respectively. Overall, the BBI of An. arabiensis was $73.1 \%$. The BBI of An. funestus from PSCs, outdoor CDC light traps and pit shelters was 27.3, 22.7 and $41.7 \%$, respectively. None of the An. funestus from indoor CDC light traps was positive for bovine blood meal. In Ahero, the overall BBI of An. funestus was $25.4 \%$. Blood meal indices for other vertebrate hosts (goat, dog and chicken) were low $(<4 \%)$.

Table 3 shows the host blood indices of An. gambiae s.s. and An. funestus in Iguhu. The HBI of An. gambiae s.s. from indoor CDC light traps and PSCs was 70.0 and $76.5 \%$, respectively, whereas the HBI of An. gambiae s.s. from outdoor CDC light traps and pit shelters was 20.0 and $23.1 \%$ respectively. The overall HBI of An. gambiae s.s. was $50.0 \%$. The HBI of An. funestus from indoor CDC light traps and PSCs was 53.8 and $61.1 \%$, respectively. In outdoor CDC light traps, very small number of fed $A n$. funestus was caught, which yielded a HBI of $50 \%$. Hence, in Iguhu, the overall HBI of An. funestus was $55.9 \%$.

The BBI of An. gambiae s.s. from PSCs, outdoor CDC light traps and pit shelters was 23.5, 40.0, and 46.1\%, respectively. None of the tested An. gambiae s.s. from indoor CDC light traps was positive for bovine blood meal. The overall BBI of An. gambiae s.s. was $28 \%$. The BBI of An. funestus from indoor CDC light traps, PSCs and outdoor CDC light traps was 15.4, 16.7, and 50\%, respectively. In Iguhu, the overall BBI of An. funestus was $17.6 \%$.

\section{Feeding preference of malaria vectors}

The overall blood meal indices and host preferences of Anopheles mosquitoes are shown in Table 4. Regardless of higher proportion of humans compared to domestic animals in Ahero, An. arabiensis showed a strong preference to feed on bovine (Forage

Table 2 Blood meal origins of An. arabiensis and An. funestus from indoor and outdoor collections in Ahero, western Kenya

\begin{tabular}{|c|c|c|c|c|c|c|c|c|}
\hline \multirow[t]{3}{*}{ Blood-meal origins } & \multicolumn{4}{|c|}{ An. arabiensis } & \multicolumn{4}{|c|}{ An. funestus } \\
\hline & \multicolumn{2}{|l|}{ Indoor } & \multicolumn{2}{|l|}{ Outdoor } & \multicolumn{2}{|l|}{ Indoor } & \multicolumn{2}{|l|}{ Outdoor } \\
\hline & Light trap & PSC & Light trap & Pit shelter & Light trap & PSC & Light trap & Pit shelter \\
\hline Number tested & 122 & 165 & 59 & 298 & 11 & 44 & 4 & 12 \\
\hline Human & $7(5.7)$ & $1(0.6)$ & $2(3.4)$ & $2(0.7)$ & $8(72.7)$ & $23(52.3)$ & $2(50.0)$ & $6(50.0)$ \\
\hline Bovine & $74(60.7)$ & $108(65.5)$ & $30(50.8)$ & $251(84.2)$ & 0 & $10(22.7)$ & $1(25.0)$ & $5(41.7)$ \\
\hline Goat & $5(4.1)$ & $5(3.0)$ & $1(1.7)$ & $4(1.3)$ & 0 & 0 & 0 & 0 \\
\hline Dog & $1(0.8)$ & $5(3.0)$ & $1(1.7)$ & $5(1.7)$ & 0 & 0 & 0 & 0 \\
\hline Chicken & $2(1.6)$ & 0 & 0 & $1(0.3)$ & 0 & 0 & 0 & 0 \\
\hline Human + bovine & $1(0.8)$ & $1(0.6)$ & 0 & 0 & 0 & $2(4.6)$ & 0 & 0 \\
\hline Human + dog & $2(1.6)$ & 0 & 0 & 0 & 0 & $3(6.8)$ & 0 & 0 \\
\hline Bovine + dog & $1(0.8)$ & $1(0.6)$ & 0 & $4(1.3)$ & 0 & 0 & 0 & 0 \\
\hline Goat + dog & 0 & $1(0.6)$ & 0 & 0 & 0 & 0 & 0 & 0 \\
\hline Dog + chicken & 0 & 0 & 0 & $1(0.3)$ & 0 & 0 & 0 & 0 \\
\hline Unknown & $29(23.8)$ & $43(26.1)$ & $25(42.4)$ & $30(10.1)$ & $3(27.3)$ & $6(13.6)$ & $1(25.0)$ & $1(8.3)$ \\
\hline $\mathrm{HBI}$ & 8.2 & 1.2 & 3.4 & 0.7 & 72.7 & 63.6 & 50.0 & 50.0 \\
\hline
\end{tabular}

$\mathrm{HBI}$ was calculated as the number of mosquito positive for human (including mixed blood meal) divided by the total number tested $\mathrm{HBI}$, human blood index; PSC, pyrethrum spray catches 
Table 3 Blood meal origins of An. gambiae s.s. and An. funestus from indoor and outdoor collections in Iguhu, western Kenya

\begin{tabular}{|c|c|c|c|c|c|c|c|c|}
\hline \multirow[t]{3}{*}{ Blood-meal origins } & \multicolumn{4}{|c|}{ An. gambiae s.s. } & \multicolumn{4}{|c|}{ An. funestus } \\
\hline & \multicolumn{2}{|l|}{ Indoor } & \multicolumn{2}{|l|}{ Outdoor } & \multicolumn{2}{|l|}{ Indoor } & \multicolumn{2}{|l|}{ Outdoor } \\
\hline & Light trap & PSC & Light trap & Pit shelter & Light trap & PSC & Light trap & Pit shelter \\
\hline Number tested & 10 & 17 & 10 & 13 & 13 & 18 & 2 & 1 \\
\hline Human & $7(70)$ & $11(64.7)$ & $2(20)$ & $3(23.1)$ & $7(53.8)$ & $11(61.1)$ & $1(50.0)$ & 0 \\
\hline Bovine & 0 & $3(17.6)$ & $4(40)$ & $6(46.1)$ & $2(15.4)$ & $3(16.7)$ & $1(50.0)$ & 0 \\
\hline Goat & 0 & 0 & 0 & 0 & $1(7.7)$ & 0 & 0 & 0 \\
\hline Dog & 0 & 0 & 0 & $1(7.7)$ & $1(7.7)$ & 0 & 0 & $1(100)$ \\
\hline Human + bovine & 0 & $1(5.9)$ & 0 & 0 & 0 & 0 & 0 & 0 \\
\hline Human + dog & 0 & $1(5.9)$ & 0 & 0 & 0 & 0 & 0 & 0 \\
\hline Unknown & $3(30)$ & $1(5.9)$ & $4(40)$ & $3(23.1)$ & $2(15.4)$ & $4(22.2)$ & 0 & 0 \\
\hline $\mathrm{HBI}$ & 70.0 & 76.5 & 20 & 23.1 & 53.8 & 61.1 & 50.0 & 0 \\
\hline
\end{tabular}

$\mathrm{HBI}$ was calculated as the number of mosquito positive for human (including mixed blood meal) divided by the total number tested $\mathrm{HBI}$, human blood index; PSC, pyrethrum spray catches

Table 4 Overall blood meal indices and host-preferences of malaria vectors from indoor and outdoor collections in Ahero and Iguhu, western Kenya

\begin{tabular}{|c|c|c|c|c|c|c|}
\hline Site and species & Parameters & Human & Bovine & Goat & Dog & Chicken \\
\hline \multicolumn{7}{|l|}{ Ahero } \\
\hline Host abundance in the area (\%) & & 27.8 & 18.8 & 4.0 & 6.0 & 43.4 \\
\hline \multirow[t]{2}{*}{ An. arabensis } & Blood index & 2.5 & 73.1 & 2.5 & 3.4 & 0.6 \\
\hline & $\mathrm{FR}(95 \% \mathrm{Cl})$ & 0.09 (0.05 to 0.13$)$ & $3.9(3.7 \text { to } 4.1)^{*}$ & $0.6(0.3$ to 0.9$)$ & 0.5 (0.3 to 0.7$)$ & $0.01(-0.03$ to 0.05$)$ \\
\hline \multirow[t]{2}{*}{ An.funestus } & Blood index & 62.0 & 25.4 & 0 & 4.2 & 0 \\
\hline & $\mathrm{FR}(95 \% \mathrm{Cl})$ & $2.2(1.8 \text { to } 2.6)^{*}$ & $1.4(0.9$ to 1.9$)$ & 0 & $0.7(-0.1$ to 1.5$)$ & 0 \\
\hline \multicolumn{7}{|l|}{ Iguhu } \\
\hline Host abundance in the area (\%) & & 27.5 & 12.4 & 2.4 & 2.5 & 55.2 \\
\hline \multirow[t]{2}{*}{ An. gambiae s.s. } & Blood index & 50 & 28 & 0 & 2.0 & 0 \\
\hline & $\mathrm{FR}(95 \% \mathrm{Cl})$ & $1.8(1.3 \text { to } 2.3)^{*}$ & $2.3(1.3 \text { to } 2.3)^{*}$ & 0 & $0.8(-0.7$ to 2.3$)$ & 0 \\
\hline \multirow[t]{2}{*}{ An.funestus } & Blood index & 55.9 & 17.6 & 2.9 & 2.9 & 0 \\
\hline & FR $(95 \% \mathrm{Cl})$ & $2.0(1.6 \text { to } 2.4)^{*}$ & $1.4(0.4$ to 2.4$)$ & $1.2(-1.2$ to 3.6$)$ & $1.2(-1.1$ to 3.5$)$ & 0 \\
\hline
\end{tabular}

$F R$, forage ratio

* Indicates the preferred host

ratio, $\mathrm{FR}=3.9,95 \% \mathrm{CI} 3.7-4.9)$. Anopheles gambiae s.s. showed preference to both human (FR $=1.8,95 \%$ CI 1.3-2.3) and bovine (FR $=2.3,95 \%$ CI 1.3-3.3). Anopheles funestus showed a preference to human in both Ahero (FR $=2.2,95 \%$ CI 1.8-2.6) and Iguhu $(\mathrm{FR}=2.0,95 \%$ CI 1.6-2.4).

\section{Sporozoite rates}

Overall, 2608 Anopheles mosquitoes comprising An. arabiensis $(\mathrm{n}=1280)$, An. gambiae s.s. $(\mathrm{n}=214)$, An. funestus $(\mathrm{n}=629)$, An. coustani $(\mathrm{n}=255)$ and An. pharoensis ( $\mathrm{n}=230)$ were tested for $P$. falciparum CSPs. Of these,
20 specimens (2 An. arabiensis, 5 An. gambiae s.s., $12 \mathrm{An}$. funestus and 1 An. coustani) were positive for CSPs.

Table 5 shows the sporozoite rates of Anopheles mosquitoes collected from indoors and outdoors. In Ahero, the sporozoite rate of $A n$. arabiensis from indoor and outdoor CDC light traps was 0.38 and $0.35 \%$, respectively. However, none of the An. arabiensis tested from PSCs and pit shelters were positive. The overall sporozoite rate of An. arabiensis was $0.16 \%$. The sporozoite rate of An. funestus from indoor CDC light traps and PSCs was 2.6 and $2.0 \%$, respectively, while this was $1.2 \%$ from both outdoor CDC light traps and pit shelters. Hence, in Ahero, the overall spozoite rate of An. funestus was 1.8\%. 
Table 5 Sporozoite rates of Anopheles mosquitoes from indoor and outdoor collections in Ahero and Iguhu, western Kenya

\begin{tabular}{|c|c|c|c|c|c|c|}
\hline \multirow[t]{2}{*}{ Study site and Anopheles sp. } & \multirow[t]{2}{*}{ Parameters } & \multicolumn{2}{|l|}{ Indoor } & \multicolumn{2}{|l|}{ Outdoor } & \multirow[t]{2}{*}{ Total } \\
\hline & & Light trap & PSC & Light trap & Pit shelter & \\
\hline \multicolumn{7}{|l|}{ Ahero } \\
\hline \multirow[t]{2}{*}{ An. arabiensis } & No tested & 263 & 264 & 286 & 447 & 1260 \\
\hline & Pf +ve (\%) & $1(0.38)$ & 0 & $1(0.35)$ & 0 & $2(0.16)$ \\
\hline \multirow[t]{2}{*}{ An. funestus } & No tested & 194 & 100 & 169 & 84 & 547 \\
\hline & $\mathrm{Pf}+\mathrm{ve}(\%)$ & $5(2.6)$ & $2(2.0)$ & $2(1.2)$ & $1(1.2)$ & $10(1.8)$ \\
\hline \multirow[t]{2}{*}{ An. coustani } & No tested & 50 & 0 & 200 & 0 & 250 \\
\hline & $\mathrm{Pf}+\mathrm{ve}(\%)$ & 0 & 0 & $1(0.5)$ & 0 & $1(0.4)$ \\
\hline \multirow[t]{2}{*}{ An. pharoensis } & No tested & 25 & 0 & 205 & 0 & 230 \\
\hline & $\mathrm{Pf}+\mathrm{ve}(\%)$ & 0 & 0 & 0 & 0 & 0 \\
\hline \multicolumn{7}{|l|}{ Iguhu } \\
\hline \multirow[t]{2}{*}{ An. gambiae s.s. } & No tested & 84 & 46 & 50 & 34 & 214 \\
\hline & Pf +ve (\%) & $3(3.6)$ & 0 & $1(2.0)$ & $1(2.9)$ & $5(2.3)$ \\
\hline \multirow[t]{2}{*}{ An. funestus } & No tested & 42 & 25 & 13 & 2 & 82 \\
\hline & Pf +ve (\%) & $1(2.4)$ & $1(4.0)$ & 0 & 0 & $2(2.4)$ \\
\hline \multirow[t]{2}{*}{ An. arabiensis } & No tested & 8 & 5 & 2 & 5 & 20 \\
\hline & Pf +ve (\%) & 0 & 0 & 0 & 0 & 0 \\
\hline \multirow[t]{2}{*}{ An. coustani } & No tested & 1 & 0 & 4 & 0 & 5 \\
\hline & $\mathrm{Pf}+\mathrm{ve}(\%)$ & 0 & 0 & 0 & 0 & 0 \\
\hline
\end{tabular}

Pf, Plasmodium falciparum; $P f+v e$, number $P$. falciparum CSP positive (rate in percent)

Moreover, one An. coustani specimen from outdoor CDC light trap was positive for CSP.

In Iguhu, the sporozoite rate of An. gambiae s.s. from indoor CDC light traps was $3.6 \%$, but none of the $A n$. gambiae s.s. tested from PSCs was positive. In contrast, the sporozoite rate of An. gambiae s.s. from outdoor CDC light traps and pit shelters was 2.0 and $2.9 \%$, respectively. Overall, the sporozoite rate of An. gambiae s.s. was 2.3\%. The sporozoite rate of An. funestus from indoor CDC light traps and PSCs was 2.4 and $4 \%$, respectively. No CSP was detected in An. funestus collected from outdoor CDC light traps and pit shelters. Thus, in Iguhu, the overall sporozoite rate of An. funestus was $2.4 \%$.

\section{Entomological inoculation rates (EIRs)}

The EIRs of Anopheles mosquitoes are shown in Table 6. In Ahero, the estimated $P$. falciparum EIR of An. arabiensis from indoor and outdoor CDC light traps was 29.6 and 27.9 infective bites/person/year (ib/p/year), respectively, whereas the EIR of An. funestus from indoor and outdoor CDC light traps was 79.0 and $15.6 \mathrm{ib} / \mathrm{p} /$ year, respectively. The overall indoor and outdoor EIR was 108.6 and $43.5 \mathrm{ib} / \mathrm{p} /$ year, respectively. About $48 \%$ of the total infective bites by $A n$. arabiensis and $16.5 \%$ by $A n$. funestus occurred outdoor. The EIR of An. arabiensis and An. funestus from PSCs was 0 and $0.92 \mathrm{ib} / \mathrm{p} / \mathrm{year}$, respectively.
In Iguhu, the estimated P. falciparum EIR of An. gambiae s.s. from indoor and outdoor CDC light traps was 18.8 and $5.5 \mathrm{ib} / \mathrm{p} /$ year, respectively, whereas the EIR of

Table 6 Entomological inoculation rates (EIR) of malaria vectors from indoor and outdoor collections in Ahero and Iguhu, western Kenya

\begin{tabular}{|c|c|c|c|c|c|}
\hline \multirow{2}{*}{$\begin{array}{l}\text { Site and spe- } \\
\text { cies }\end{array}$} & \multirow[t]{2}{*}{ Parameters } & \multicolumn{2}{|l|}{ Indoor } & \multicolumn{2}{|l|}{ Outdoor } \\
\hline & & Light trap & PSC & Light trap & Pit shelter \\
\hline \multicolumn{6}{|l|}{ Ahero } \\
\hline \multirow{2}{*}{$\begin{array}{l}\text { An. arabi- } \\
\text { ensis }\end{array}$} & $S R$ & 0.38 & 0 & 0.35 & 0 \\
\hline & EIR & 29.6 & 0 & 27.9 & 0 \\
\hline \multirow[t]{2}{*}{ An. funestus } & $S R$ & 2.6 & 2.0 & 1.2 & 1.2 \\
\hline & $E I R$ & 79.0 & 0.92 & 15.6 & 0.05 \\
\hline \multirow[t]{2}{*}{ An. coustani } & $S R$ & 0 & 0 & 0.5 & 0 \\
\hline & $E I R$ & 0 & 0 & 16.8 & 0 \\
\hline \multicolumn{6}{|l|}{ Iguhu } \\
\hline \multirow{2}{*}{$\begin{array}{l}\text { An. gambiae } \\
\text { S.s. }\end{array}$} & $S R$ & 3.6 & 0 & 2.0 & 2.9 \\
\hline & $E I R$ & 18.8 & 0 & 5.5 & 0.17 \\
\hline \multirow[t]{2}{*}{ An. funestus } & $S R$ & 2.4 & 4.0 & 0 & 0 \\
\hline & EIR & 5.7 & 0.82 & 0 & 0 \\
\hline \multirow[t]{2}{*}{ An. arabiensis } & $\mathrm{SR}$ & 0 & 0 & 0 & 0 \\
\hline & $E I R$ & 0 & 0 & 0 & 0 \\
\hline
\end{tabular}

SR, sporozoite rate in percent; EIR, annual entomological inoculation rate measured as the number of infective bites/person/year; PSC, pyrethrum spray catch 
An. funestus from indoor and outdoor CDC light traps was 5.7 and $0 \mathrm{ib} / \mathrm{p} /$ year, respectively. The overall indoor and outdoor EIR was 24.5 and $5.5 \mathrm{ib} / \mathrm{p} /$ year, respectively. About $22.6 \%$ of the total infective bites by An. gambiae s.s. occurred outdoor. The EIR of An. gambiae s.s. and An. funestus from PSCs was 0 and $0.82 \mathrm{ib} / \mathrm{p} /$ year, respectively.

\section{Discussion}

This study showed that An. arabiensis was the most abundant anopheline species in Ahero (lowland), whereas $A n$. gambiae s.s. was the most abundant species in Iguhu (highland) sites of western Kenya. An. funestus was the second most abundant species in both sites, which is consistent with previous studies $[5,6]$.

Anopheles arabiensis showed increased exophagic tendency in the study area when compared with the findings of studies conducted before the scale up of vector control interventions [22, 41]. For instance, studies by Githeko et al. in 1990s, when ITN coverage was negligeable, showed that $A n$. arabiensis was two times more likely to bite indoors than outdoors [22]. In the present study, the outdoor biting density of An. arabiensis was higher than indoor. The increased outdoor host-seeking tendency of An. arabiensis in this study compared to the previous reports might be due to the scale-up of ITNs. Bayoh et al. also noted that $A n$. arabiensis was more likely to bite outdoors in western Kenya when compared with data collected before the scale-up of ITNs [19]. Moreover, An. arabiensis showed highly exophilic behaviour in this study, with significantly higher outdoor resting density than indoor resting density.

The proportion of $A n$. arabiensis has been increasing in western Kenya highlands. Until 2002, An. gambiae s.s. was the only member of An. gambiae s.l. complex reported in western Kenya highlands $>1400 \mathrm{~m}$ a.s.l. [25, 42]. The proportion of An. arabiensis was reported to be $0.8 \%$ in 2003 [43] and reached $9.2 \%$ in 2010 [5]. In this study, the proportion of adult An. arabiensis increased to $13 \%$. A recent study reported a higher proportion of An. arabiensis (38.2\%) in larval population [44]. The continued proportional increase in $A n$. arabiensis population might be due to the increased ITN coverage $[9,10]$ and/or the zoophilic and exophagic/exophilic behaviour of this species or due to species shift. Other factors such as climatic and environmental change, which resulted in increased temperature or availability of more habitats in the area, might have also contributed as this was found to favor An. arabiensis [45]. Such shift in vector species composition could undermine the efficacy of ITNs as the interventions do not target zoophilic and exophilic vector species which avoids the lethal effect of ITNs and sustain residual malaria transmission [46].
Anopheles gambiae s.s. showed endophagic behaviour, with higher indoor host-seeking density than outdoor. This is in agreement with the earlier reports by Githeko et al. [22]. Recent studies in western Kenya have also showed that $A n$. gambiae s.s. was more likely to seek hosts indoor than outdoor $[19,47]$. In contrast, studies in Bioko Island, Equatorial Guinea showed that An. gambiae s.s. seek hosts outdoor than indoor [48]. This difference might be due to the variation in molecular forms of An. gambiae s.s. (S and M/Anopheles coluzzii) from Kenya and Equatorial Guinea [49] although the variability in host-seeking behaviour between the two molecular forms is not yet explicitly described.

It is unusual that An. gambiae s.s. showed similar feeding preference to human and bovine. Two decades ago, the HBI of indoor resting An. gambiae s.s. in western Kenya and other parts of the country was $96-97 \%$, an indication that they had fed exclusively on humans [21, $23,50]$. In this study, the overall HBI of An. gambiae s.s. was only $50.0 \%$ although predominantly from indoor collection. Compared to the earlier studies conducted in western Kenya before ITNs were used in large scale [21, 23], the HBI of indoor resting An. gambiae s.s. has significantly dropped by $20 \%$ and the drop was entirely replaced by BBI. For outdoor resting An. gambiae s.s., the BBI reached up to $46 \%$. Similar reduction in HBI and increment in BBI has also been reported recently $[7,15]$. This suggests an increasing tendency of An. gambiae s.s. to feed on bovine following the increased ITN coverage in the western Kenya highlands.

Anopheles funestus s.s. was the predominant species among Anopheles funestus group in the study area. Similar findings were reported in Tanzania [51]. Kweka et al. [52] also found that An. funestus s.s. was the predominant sibling species in larvae population in western Kenya. However, there was significant difference in terms of the relative proportion of An. funestus s.s. between adult and larvae population. In this study, An. funestus s.s. accounted for $98.1 \%$ of the adult An. funestus s.l. population. In contrast, Kweka et al. found only $32.9 \% A n$. funestus s.s. in larvae population. This difference could be due to the presence of other zoophilic and exophilic sibling species of An. funestus s.l. in the larvae that do not bite or rest indoor or around human dwellings.

Anopheles funestus showed anthropophagic behaviour in both study sites, feeding predominantly on human. The anthrophagic behaviour of An. funestus was frequently observed in Kenya $[21,50]$ and elsewhere in Africa [5356]. Nevertheless, they also fed on bovine, with higher BBI than the previous reports [21, 50, 53-56].

The secondary vectors, An. pharoensis and An. coustani showed exophagic behaviour, with significantly higher outdoor host-seeking density than indoor. Other 
studies in Kenya [41, 57] and elsewhere in Africa [5860] reported similar phenomenon for these species. It is worth mentioning that both An. pharoensis and An. coustani were very rare in both indoor resting collections and pit shelters despite their preponderance in CDC light traps. Hence, further studies are required to find out the potential resting places of An. pharoensis and An. coustani.

The EIR data showed that the majority of malaria transmission by An. gambiae s.s. and An. funestus occurred indoors, while An. arabiensis contributed almost equally to both outdoor and indoor transmission. The higher indoor EIRs despite high ITN coverage could be attributed to inconsistent ITN use [61], increasing insecticide resistance among vectors $[5,8]$, and shifts in malaria vector biting times from mid-night to early evening and morning when people are still indoor but unprotected by ITNs [47, 62]. However, the magnitude of the outdoor EIRs was also considerably high compared to previous reports [19]. The ongoing shifts in vector species composition and changes in vector behaviours might have contributed to the high outdoor EIRs.

In addition to the primary vectors, a single specimen of An. coustani from outdoor CDC light trap was found to be positive for P. falciparum CSP based on ELISA, although not yet confirmed by PCR. Studies are increasingly reporting the importance of the secondary vectors in residual malaria transmission [57, 60,63-65]. Several studies have demonstrated the susceptibility of An. coustani to $P$. falciparum infection $[57,59,60,66]$. Although ELISA technique is not specific enough to incriminate zoophagic mosquitoes as a vector [33], a recent study in Madagascar confirmed the presence of Plasmodium CSP in An. coustani by both ELISA and PCR [60], suggesting that this species could play a role in outdoor malaria transmission.

\section{Conclusion}

Anopheles arabiensis was highly exophilic and zoophagic. Anopheles gambiae s.s. showed an increasing tendency to feed on bovine while An. funestus showed anthropophagic behaviour. While most of malaria transmission occurred indoor, the magnitude of outdoor transmission was considerably high. Additional control tools that complement the existing interventions are required to control residual transmission. Further studies are required to comprehend the role of secondary vectors in malaria transmission.

\section{Abbreviations}

BBI: bovine blood index; CDC: Centers for Disease Control and Prevention; CSP: circumsporozoite protein; EIR: entomological inoculation rate; ELISA: enzymelinked immunosorbent assay; FR: forage ratio; HBI: human blood index; IRS: indoor residual spray; ITN: insecticide-treated net; PCR: polymerase chain reaction; PSC: pyrethrum spray catch.

\section{Authors' contributions}

TD, DY, AKG and GY designed the study protocol. TD involved in data collection, laboratory work and data analysis. GZ and ML participated in data analysis. HA supervised data collection and laboratory work. TD drafted the manuscript. DY, AKG, GY critically reviewed the manuscript. All authors read and approved the final manuscript.

\section{Author details \\ ${ }^{1}$ Department of Medical Laboratory Sciences, College of Health Sciences, Jimma University, Jimma, Ethiopia. ${ }^{2}$ Centre for Global Health Research, Kenya Medical Research Institute, Kisumu, Kenya. ${ }^{3}$ Tropical and Infectious Diseases Research Center (TIDRC), Jimma University, Jimma, Ethiopia. ${ }^{4}$ Program in Pub- lic Health, College of Health Sciences, University of California at Irvine, Irvine, CA 92697, USA. ${ }^{5}$ School of Public Health, Maseno University, Kisumu, Kenya.}

\section{Acknowledgements}

The authors would like to acknowledge all entomology technicians of Climate and Human Health Research Unit, Kenya Medical Research Institute for their technical support in the field and laboratory. We thank the communities of Ahero and lguhu for their willingness to participate in the study. This study is published with the permission of the Director, Kenya Medical Research Institute.

\section{Competing interests}

The authors declare that they have no competing interests.

\section{Availability of data and materials}

The datasets used for the current study are available from the corresponding author on reasonable request.

\section{Ethics approval and consent to participate}

Ethical approval for the study was obtained from Ethical Review Board of Kenya Medical Research Institute and University of California, Irvine. Permission was sought from chief of each study site. Informed consent was obtained from heads of the households.

\section{Funding}

This work was supported by Grants from the National Institutes of Health (R01 Al050243, U19 Al129326 and D43 TW001505).

\section{Publisher's Note}

Springer Nature remains neutral with regard to jurisdictional claims in published maps and institutional affiliations.

Received: 20 July 2017 Accepted: 28 October 2017

Published online: 06 November 2017

\section{References}

1. WHO. World Malaria Report 2015. Geneva: World Health Organization; 2015

2. Shargie EB, Ngondi J, Graves PM, Getachew A, Hwang J, Gebre T, et al. Rapid increase in ownership and use of long-lasting insecticidal nets and decrease in prevalence of malaria in three regional States of Ethiopia (2006-2007). J Trop Med. 2010;2010:e750978.

3. Bhattarai A, Ali AS, Kachur SP, Mårtensson A, Abbas AK, Khatib R, et al. Impact of artemisinin-based combination therapy and insecticidetreated nets on malaria burden in Zanzibar. PLoS Med. 2007;4:e309.

4. Otten M, Aregawi M, Were W, Karema C, Medin A, Bekele W, et al. Initial evidence of reduction of malaria cases and deaths in Rwanda and Ethiopia due to rapid scale-up of malaria prevention and treatment. Malar J. 2009;8:14.

5. Zhou G, Afrane YA, Vardo-Zalik AM, Atieli H, Zhong D, Wamae P. Changing patterns of malaria epidemiology between 2002 and 2010 in Western Kenya: the fall and rise of malaria. PLOS ONE. 2011;6:e20318. 
6. Ototo EN, Mbugi JP, Wanjala CL, Zhou G, Githeko AK, Yan G. Surveillance of malaria vector population density and biting behaviour in western Kenya. Malar J. 2015;14:244

7. Ndenga BA, Mulaya NL, Musaki SK, Shiroko JN, Dongus S, Fillinger U. Malaria vectors and their blood-meal sources in an area of high bed net ownership in the western Kenya highlands. Malar J. 2016;15:76.

8. Ochomo EO, Bayoh NM, Walker ED, Abongo BO, Ombok MO, Ouma C, et al. The efficacy of long-lasting nets with declining physical integrity may be compromised in areas with high levels of pyrethroid resistance. Malar J. 2013;12:368.

9. Bayoh MN, Mathias DK, Odiere MR, Mutuku FM, Kamau L, Gimnig JE, et al. Anopheles gambiae: historical population decline associated with regional distribution of insecticide-treated bed nets in western Nyanza Province, Kenya. Malar J. 2010;9:62.

10. Mwangangi JM, Mbogo CM, Orindi BO, Muturi EJ, Midega JT, Nzovu $\mathrm{J}$, et al. Shifts in malaria vector species composition and transmission dynamics along the Kenyan coast over the past 20 years. Malar J. 2013;12:13.

11. Russell TL, Lwetoijera DW, Maliti D, Chipwaza B, Kihonda J, Charlwood JD, et al. Impact of promoting longer-lasting insecticide treatment of bed nets upon malaria transmission in a rural Tanzanian setting with preexisting high coverage of untreated nets. Malar J. 2010;9:187.

12. Derua YA, Alifrangis M, Hosea KM, Meyrowitsch DW, Magesa SM, Pedersen EM, et al. Change in composition of the Anopheles gambiae complex and its possible implications for the transmission of malaria and lymphatic filariasis in north-eastern Tanzania. Malar J. 2012;11:188.

13. Russell TL, Govella NJ, Azizi S, Drakeley CJ, Kachur SP, Killeen GF. Increased proportions of outdoor feeding among residual malaria vector populations following increased use of insecticide-treated nets in rural Tanzania. Malar J. 2011;10:80.

14. Durnez L, Coosemans M. Residual transmission of malaria: an old issue for new approaches. In: Manguin S, editor. Anopheles mosquitoes-new insights into malaria vectors; 2013. p. 671-704.

15. Mutuku FM, King CH, Mungai P, Mbogo C, Mwangangi J, Muchiri EM, et al. Impact of insecticide-treated bed nets on malaria transmission indices on the south coast of Kenya. Malar J. 2011;10:356.

16. Lefèvre T, Gouagna L-C, Dabiré KR, Elguero E, Fontenille D, Renaud F, et al. Beyond nature and nurture: phenotypic plasticity in blood-feeding behavior of Anopheles gambiae s.s. when humans are not readily accessible. Am J Trop Med Hyg. 2009;81:1023-9.

17. Reddy MR, Overgaard HJ, Abaga S, Reddy VP, Caccone A, Kiszewski AE, et al. Outdoor host seeking behaviour of Anopheles gambiae mosquitoes following initiation of malaria vector control on Bioko Island, Equatorial Guinea. Malar J. 2011:10:184

18. Meyers Jl, Pathikonda S, Popkin-Hall ZR, Medeiros MC, Fuseini G, Matias A, et al. Increasing outdoor host-seeking in Anopheles gambiae over 6 years of vector control on Bioko Island. Malar J. 2016;15:239.

19. Bayoh MN, Walker ED, Kosgei J, Ombok M, Olang GB, Githeko AK, et al. Persistently high estimates of late night, indoor exposure to malaria vectors despite high coverage of insecticide treated nets. Parasit Vectors. 2014;7:380.

20. Githeko A, Ototo E, Guiyun Y. Progress towards understanding the ecology and epidemiology of malaria in the western Kenya highlands: opportunities and challenges for control under climate change risk. Acta Trop. 2012;121:19-25.

21. Githeko A, Service M, Mbogo C, Atieli F, Juma F. Origin of blood meals in indoor and outdoor resting malaria vectors in western Kenya. Acta Trop. 1994;58:307-16

22. Githeko AK, Adungo NI, Karanja DM, Hawley WA, Vulule JM, Seroney IK, et al. Some observations on the biting behavior of Anopheles gambiae s.s, Anopheles arabiensis, and Anopheles funestus and their implications for malaria control. Exp Parasitol. 1996;82:306-15.

23. Shililu J, Maier W, Seitz H, Orago A. Seasonal density, sporozoite rates and entomological inoculation rates of Anopheles gambiae and Anopheles funestus in a high altitude sugarcane growing zone in western Kenya. Trop Med Int Health. 1998;3:706-10.

24. Munyekenye OG, Githeko AK, Zhou G, Mushinzimana E, Minakawa N, Yan G. Plasmodium falciparum spatial analysis, western Kenya highlands. Emerg Infect Dis. 2005;11:1571-7.
25. Githeko AK, Ayisi JM, Odada PK, Atieli FK, Ndenga BA, Githure Jl, et al. Topography and malaria transmission heterogeneity in western Kenya highlands: prospects for focal vector control. Malar J. 2006;5:107.

26. WHO. Manual on practical entomology in malaria. Geneva: World Health Organization; 1995.

27. Muirhead-Thomson R. A pit shelter for sampling outdoor mosquito populations. Bull World Health Organ. 1958;19:1116-8.

28. Gillies M, Coetzee M. A supplement to the Anophelinae of Africa South of the Sahara. Public South Afr Instit Med Res. 1987;55:1-143.

29. Scott JA, Brogdon WG, Collins FH. Identification of single specimens of the Anopheles gambiae complex by the polymerase chain reaction. Am J Trop Med Hyg. 1993;49:520-9.

30. Koekemoer L, Kamau L, Hunt R, Coetzee M. A cocktail polymerase chain reaction assay to identify members of the Anopheles funestus (Diptera: Culicidae) group. Am JTrop Med Hyg. 2002;66:804-11.

31. Beier JC, Perkins PV, Wirtz RA, Koros J, Diggs D. Bloodmeal identification by direct enzyme-linked immunosorbent assay (ELISA), tested on Anopheles (Diptera: Culicidae) in Kenya. DTIC Doc. 1988;25:9-16.

32. Beier JC, Perkins PV, Wirtz RA, Whitmire RE, Mugambi M. Field evaluation of an enzymelinked immunosorbent assay (ELISA) for Plasmodium falciparum sporozoite detection in anopheline mosquitoes from Kenya. DTIC Doc. 1987:36:459-68.

33. Wirtz R, Burkot T, Graves P, Andre R. Field evaluation of enzyme-linked immunosorbent assays for Plasmodium falciparum and Plasmodium vivax sporozoites in mosquitoes (Diptera: Culicidae) from Papua New Guinea. J Med Entomol. 1987;24:433-7.

34. Garrett-Jones C. The human blood index of malaria vectors in relation to epidemiological assessment. Bull World Health Organ. 1964;30:241-61.

35. Pappa V, Reddy M, Overgaard HJ, Abaga S, Caccone A. Estimation of the human blood index in malaria mosquito vectors in Equatorial Guinea after indoor antivector interventions. Am J Trop Med Hyg. 2011;84:298-301.

36. Hess $\mathrm{A}$, Hayes $\mathrm{RO}$, Tempelis $\mathrm{C}$. The use of the forage ratio technique in mosquito host preference studies. Mosq News. 1968;28:386-9.

37. Manly B, McDonald L, Thomas D, McDonald TL, Erickson WP. Resource selection by animals: statistical design and analysis for field studies. New York: Springer Science \& Business Media; 2007.

38. Lines J, Curtis C, Wilkes T, Njunwa K. Monitoring human-biting mosquitoes (Diptera: Culicidae) in Tanzania with light-traps hung beside mosquito nets. Bull Entomol Res. 1991;81:77-84.

39. Drakeley C, Schellenberg D, Kihonda J, Sousa C, Arez A, Lopes D, et al. An estimation of the entomological inoculation rate for Ifakara: a semi-urban area in a region of intense malaria transmission in Tanzania. Trop Med Int Health. 2003:8:767-74.

40. WHO. Malaria entomology and vector control: learner's guide. Trial Edition HIV/AIDS, tuberculosis and malaria, roll back malaria. Geneva: World Health Organization; 2003.

41. Githeko A, Mbogo C, Atieli F, Juma F. Sampling Anopheles arabiensis, A. gambiae sensu lato and $A$. funestus (Diptera: Culicidae) with CDC lighttraps near a rice irrigation area and a sugarcane belt in western Kenya. Bull Entomol Res. 1994;84:319-24.

42. Minakawa N, Sonye G, Mogi M, Githeko A, Yan G. The effects of climatic factors on the distribution and abundance of malaria vectors in Kenya. J Med Entomol. 2002;39:833-41.

43. Ndenga B, Githeko A, Omukunda E, Munyekenye G, Atieli H, Wamai P, et al. Population dynamics of malaria vectors in western Kenya highlands. J Med Entomol. 2006:43:200-6.

44. Kweka EJ, Munga S, Himeidan Y, Githeko AK, Yan G. Assessment of mosquito larval productivity among different land use types for targeted malaria vector control in the western Kenya highlands. Parasit Vectors. 2015;8:356.

45. Afrane YA, Zhou G, Lawson BW, Githeko AK, Yan G. Life-table analysis of Anopheles arabiensis in western Kenya highlands: effects of land covers on larval and adult survivorship. Am J Trop Med Hyg. 2007;77:660-6.

46. Okumu FO, Kiware SS, Moore SJ, Killeen GF. Mathematical evaluation of community level impact of combining bed nets and indoor residual spraying upon malaria transmission in areas where the main vectors are Anopheles arabiensis mosquitoes. Parasit Vectors. 2013;6:17.

47. Cooke MK, Kahindi SC, Oriango RM, Owaga C, Ayoma E, Mabuka D, et al. 'A bite before bed': exposure to malaria vectors outside the times of net use in the highlands of western Kenya. Malar J. 2015;14:259. 
48. Overgaard HJ, Reddy VP, Abaga S, Matias A, Reddy MR, Kulkarni V, et al. Malaria transmission after five years of vector control on Bioko Island, Equatorial Guinea. Parasit Vectors. 2012;5:253.

49. Lehmann T, Licht M, Elissa N, Maega B, Chimumbwa J, Watsenga F, et al. Population structure of Anopheles gambiae in Africa. J Hered. 2003;94:133-47.

50. Mwangangi JM, Mbogo CM, Nzovu JG, Githure Jl, Yan G, Beier JC. Bloodmeal analysis for anopheline mosquitoes sampled along the Kenyan coast. J Am Mosq Control Assoc. 2003;19:371-5.

51. Derua YA, Alifrangis M, Magesa SM, Kisinza WN, Simonsen PE. Sibling species of the Anopheles funestus group, and their infection with malaria and lymphatic filarial parasites, in archived and newly collected specimens from northeastern Tanzania. Malar J. 2015;14:104

52. Kweka EJ, Kamau L, Munga S, Lee M-C, Githeko AK, Yan G. A first report of Anopheles funestus sibling species in western Kenya highlands. Acta Trop. 2013;128:158-61.

53. Tanga M, Ngundu W, Tchouassi P. Daily survival and human blood index of major malaria vectors associated with oil palm cultivation in Cameroon and their role in malaria transmission. Trop Med Int Health. 2011;16:447-57.

54. Das S, Henning TC, Simubali L, Hamapumbu H, Nzira L, Mamini E, et al. Underestimation of foraging behaviour by standard field methods in malaria vector mosquitoes in southern Africa. Malar J. 2015;14:12.

55. Mzilahowa T, Hastings IM, Molyneux ME, McCall PJ. Entomological indices of malaria transmission in Chikhwawa district, Southern Malawi. Malar J. 2012;11:380.

56. Dadzie SK, Brenyah R, Appawu MA. Role of species composition in malaria transmission by the Anopheles funestus group (Diptera: Culicidae) in Ghana. J Vector Ecol. 2013;38:105-10.

57. Mwangangi JM, Muturi EJ, Muriu SM, Nzovu J, Midega JT, Mbogo C. The role of Anopheles arabiensis and Anopheles coustani in indoor and outdoor malaria transmission in Taveta District, Kenya. Parasit Vectors. 2013;6:114.
58. Taye B, Lelisa K, Emana D, Asale A, Yewhalaw D. Seasonal dynamics, longevity, and biting activity of anopheline mosquitoes in southwestern Ethiopia. J Insect Sci. 2016;16:6.

59. Antonio-Nkondjio C, Kerah CH, Simard F, Awono-Ambene P, Chouaibou $M$, Tchuinkam T, et al. Complexity of the malaria vectorial system in Cameroon: contribution of secondary vectors to malaria transmission. J Med Entomol. 2006:43:1215-21.

60. Nepomichene TN, Tata E, Boyer S. Malaria case in Madagascar, probable implication of a new vector, Anopheles coustani. Malar J. 2015;14:475.

61. Atieli HE, Zhou G, Afrane Y, Lee M-C, Mwanzo I, Githeko AK, et al. Insecticide-treated net (ITN) ownership, usage, and malaria transmission in the highlands of western Kenya. Parasit Vectors. 2011;4:113.

62. Wamae P, Githeko A, Otieno G, Kabiru E, Duombia S. Early biting of the Anopheles gambiae s.s and its challenges to vector control using insecticide treated nets in western Kenya highlands. Acta Trop. 2015;150:136-42.

63. Stevenson J, Laurent BS, Lobo NF, Cooke MK, Kahindi SC, Oriango RM et al. Novel vectors of malaria parasites in the western highlands of Kenya. Emerg Infect Dis. 2012;18:1547-50.

64. Laurent BS, Cooke M, Krishnankutty SM, Asih P, Mueller JD, Kahindi S, et al. Molecular characterization reveals diverse and unknown malaria vectors in the western Kenyan highlands. Am J Trop Med Hyg. 2016;94:327-35.

65. Stevenson JC, Simubali L, Mbambara S, Musonda M, Mweetwa S, Mudenda T, et al. Detection of Plasmodium falciparum infection in Anopheles squamosus (Diptera: Culicidae) in an area targeted for malaria elimination, southern Zambia. J Med Entomol. 2016;53:1482-7.

66. Degefa T, Zeynudin A, Godesso A, Michael YH, Eba K, Zemene E, et al. Malaria incidence and assessment of entomological indices among resettled communities in Ethiopia: a longitudinal study. Malar J. 2015;14:24.

\section{Submit your next manuscript to BioMed Central and we will help you at every step:}

- We accept pre-submission inquiries

- Our selector tool helps you to find the most relevant journal

- We provide round the clock customer support

- Convenient online submission

- Thorough peer review

- Inclusion in PubMed and all major indexing services

- Maximum visibility for your research

Submit your manuscript at www.biomedcentral.com/submit
O Biomed Central 